Психология. Журнал Высшей школы экономики.

2018. T. 15. № 1. C. 164-173. DOI: 10.17323/1813-8918-2018-1-164-173

Короткие сообщения

\title{
ПРОСТРАНСТВЕННАЯ АВТОКОРРЕЛЯЦИЯ ОБРАЗОВАТЕЛЬНЫХ ДОСТИЖЕНИЙ В РОССИЙСКОЙ ФЕДЕРАЦИИ
}

\begin{abstract}
А.А. ГРИГОРЬЕВ
${ }^{a}$ ФГБУН Институт психологии РАН, 129366, Москва, ул. Ярославская, д. 13, к. 1

Резюме

Пространственная автокорреляция является мерой того, в какой степени расположенные вблизи друг от друга объекты характеризуются тенденцией иметь сходные значения по некоторому показателю. С недавнего времени в психологии стала изучаться пространственная корреляция национального IQ (среднего интеллекта в стране). В настоящей статье представлены результаты расчета пространственной автокорреляции образовательных достижений (оцененных из среднего балла ЕГЭ лиц, поступивших в бюджетные вузы в 2014 г.), преступности, рождаемости, младенческой смертности, урбанизации, миграционного сальдо и доходов населения для 75 регионов (субъектов) РФ. Эти результаты показали, что, хотя все перечисленные показатели характеризуются пространственной автокорреляцией, ее величина варьирует. Низкой пространственной автокорреляцией характеризуются миграционное сальдо, доходы населения и образовательные достижения. Низкая пространственная автокорреляция миграционного сальдо в некоторой мере, возможно, обусловлена тем, что даже небольшое различие в условиях жизни между соседними регионами может вызвать довольно интенсивную миграцию из региона с худшими условиями в регионы с лучшими условиями, в том числе в соседний, про лучшие условия в котором мигрантам должно быть известно. Низкая пространственная автокорреляция доходов населения объясняется, вероятно, тем, что в РФ доходы населения региона в значительной степени определяются добычей нефти и газа, а местонахождение полезных ископаемых едва ли характеризуется пространственной автокорреляцией на уровне таких территориальных единиц, как субъекты РФ. Пространственную автокорреляцию образовательных достижений несколько снижает, возможно, то, что их оценки были получены посредством усреднения баллов ЕГЭ для всех специальностей всех вузов региона без учета возможных различий регионов по престижности специальностей и числу бюджетных мест в вузах.
\end{abstract}

Ключевые слова: пространственная автокорреляция, образовательные достижения, миграционное сальдо.

Исследование поддержано грантом РНФ, проект № 17-78-30035. 
Пространственная автокорреляция является мерой того, в какой степени расположенные вблизи друг от друга объекты (школы, населенные пункты, районы города и т.д.) характеризуются тенденцией иметь сходные значения по некоторому показателю. Одним из ее индексов является I Морана. I Морана представляет собой аналог коэффициента корреляции, равного произведению моментов, в который введены веса, зависящие от значений в ячейках матрицы близости объектов. Матрица близости объектов может определяться по-разному. Например, если два объекта имеют общую границу, в соответствующую ячейку матрицы близости записывается 1, в противном случае 0. Или, если расстояние между двумя объектами не превышает некоторого порога, в соответствующую ячейку матрицы близости ставится 1 , в другом случае 0 . От того, как определяется матрица близости (в частности, от того, какое расстояние считается пороговым), зависит величина I Морана. Эта величина обычно принимает значения от -1 до +1 , но теоретически может и выходить за них; величина, равная $-1 /(1-n)$, где $\mathrm{n}-$ число объектов, означает отсутствие пространственной автокорреляции.

Пространственную автокорреляцию показателя в популяционных исследованиях можно интерпретировать по аналогии с ретестовой надежностью измерений. Высокая ретестовая надежность означает, что данные не представляют собой набора значений случайной величины и что измеряемый показатель стабилен внутри интервала времени между измерениями. Ее отсутствие или снижение имеет одно из этих двух объяснений. Сходным образом высокая пространственная автокорреляция означает, что данные не представляют собой набора значений случайной величины и что измеряемый показатель стабилен внутри расстояния между объектами, которые считаются близкими. Можно вообразить ситуации, в которых пространственная корреляция будет отсутствовать или снижена. Если, например, мы будем предьявлять маленьким детям, проживающим в разных регионах, тесты на абстрактное мышление, то результаты регионов будут, скорее всего, набором случайных значений, а пространственная автокорреляция тестовых баллов - мало отличающейся от нуля. Если достаточно большому числу школ, расположенных в разных частях города, будет придан особый статус, что приведет к росту их образовательных достижений, это также будет иметь последствием снижение пространственной автокорреляции образовательных достижений, так как обусловит увеличение различий между некоторыми соседними школами. Из сказанного вытекает, что определению пространственной автокорреляции в популяционных исследованиях следует придавать не меньшее значение, чем обычной оценке надежности психологических измерений. В случае же получения низких ее значений следует попытаться найти факторы, обусловившие пространственную нестабильность показателя.

Между тем, несмотря на то, что в ряде научных дисциплин пространственная автокорреляция достаточно прочно вошла в оборот, в психологии 
ее анализ стал использоваться только в самые последние годы. В двух работах (Gelade, 2008; Hassall, Sherratt, 2011) определялась пространственная автокорреляция национального IQ (среднего интеллекта в странах) для больших множеств стран. В одной работе (Григорьев, Сухановский, 2015) рассчитывалась пространственная автокорреляция национального IQ, образовательных достижений, открытости опыту и творческих достижений для множества 20 европейских стран. В настоящей статье определяется пространственная автокорреляция образовательных достижений и нескольких других показателей для 75 регионов Российской Федерации.

\section{Метод}

\section{Регионы}

В анализе были использованы данные 77 субъектов РФ, по которым имелись сведения об образовательных достижениях за 2014 г. и которые имеют сухопутную границу хотя бы с одним из других регионов. Данные по Санкт-Петербургу и Ленинградской области, а также по Москве и Московской области были объединены. Таким образом, анализ проводился на множестве 75 региоHOB.

\section{Показатели}

Оценки образовательных достижений были взяты из работы А.А. Григорьева с соавт. (Grigoriev et al., 2016), в которой эти оценки были выведены из данных о среднем балле ЕГЭ лиц, поступивших в бюджетные вузы в 2014 г. (Министерство образования и науки РФ, 2014).

Баллы ЕГЭ были усреднены по регионам; полученные региональные средние были выражены в шкале EQ (Educational Quotient) со средним 100 и стандартным отклонением 15 (аналог шкалы IQ). Среднее и стандартное отклонение, использованные для перевода в шкалу EQ, были средним и стандартным отклонением не усредненных по регионам данных.

Статистические данные по преступности, рождаемости, младенческой смертности, урбанизации, миграции и доходам населения за 2012 г. были взяты из этой же работы. Показателем преступности является число зарегистрированных преступлений на 100000 человек населения, показатель рождаемости - число родившихся на 1000 человек населения, показатель младенческой смертности - число умерших в течение первого года жизни из 1000 родившихся живыми, урбанизация - доля городского населения, показатель миграции (миграционное сальдо) разность между числом прибывших в регион и выбывших из региона, доходы населения - средний доход на душу населения в месяц в рублях. Данные по этим показателям доступны на сайте Федеральной службы государственной статистики (Регионы России. Социально-экономические показатели. 2013, 2013).

\section{Результаты и обсуждение}

Данные по образовательным достижениям, преступности, рождаемости, младенческой смертности, урбанизации, миграции и доходам 
населения для 75 регионов представлены в таблице 1. Для каждого из этих показателей был рассчитан индекс пространственной автокорреляции (I Морана). Матрица близости регионов определялась на основании наличия общей границы: если между двумя регионами есть общая граница, то в соответствующую ячейку матрицы записывалась 1 , в противном случае 0. Значения I Moрана приведены в последней строчке таблицы. Корреляции показателей вычислены на несколько большем множестве регионов РФ (Grigoriev et al., 2016).

Как явствует из последней строчки таблицы 1, и образовательные

Таблица 1

Образовательные достижения, преступность, рождаемость, младенческая смертность, урбанизация, миграция и доходы населения в 75 регионах РФ и значения I Морана для этих показателей

\begin{tabular}{|l|c|c|c|c|c|c|c|}
\hline \multicolumn{1}{|c|}{ Регион } & $\mathbf{E Q}$ & $\mathbf{I I}$ & $\mathbf{P}$ & $\mathbf{M C}$ & $\mathbf{y}$ & $\mathbf{M}$ & Д \\
\hline Республика Алыгея & 83 & 919 & 12.9 & 7.9 & 47 & 49 & 17025 \\
\hline Республика Башкортостан & 99 & 1610 & 14.6 & 7.9 & 61.1 & -22 & 21259 \\
\hline Республика Бурятия & 80 & 2419 & 17.5 & 8.3 & 59 & -47 & 17119 \\
\hline Республика Дагестан & 84 & 464 & 19.1 & 15.2 & 45.1 & -82 & 20648 \\
\hline Республика Ингушетия & 100 & 410 & 21.4 & 12.2 & 39.9 & 92 & 12375 \\
\hline $\begin{array}{l}\text { Кабардино-Балкарская } \\
\text { Республика }\end{array}$ & 82 & 1024 & 16 & 8.7 & 54.1 & -72 & 13681 \\
\hline Республика Калмыкия & 92 & 1311 & 15 & 7.7 & 44.7 & -138 & 10184 \\
\hline $\begin{array}{l}\text { Карачаево-Черкесская } \\
\text { Республика }\end{array}$ & 86 & 777 & 13.7 & 10.6 & 42.9 & -99 & 13354 \\
\hline Республика Карелия & 101 & 1799 & 12.6 & 7.6 & 78.8 & -15 & 20037 \\
\hline Республика Коми & 98 & 1986 & 14 & 5.9 & 77.3 & -122 & 26787 \\
\hline Республика Марий Эл & 94 & 1373 & 14.2 & 8.3 & 64.3 & -36 & 12538 \\
\hline Республика Мордовия & 99 & 950 & 10 & 8 & 61.3 & -38 & 13063 \\
\hline Республика Саха (Якутия) & 96 & 1269 & 17.8 & 9.6 & 64.9 & -87 & 28457 \\
\hline $\begin{array}{l}\text { Республика Северная } \\
\text { Осетия - Алания }\end{array}$ & 85 & 886 & 15.3 & 11.6 & 63.9 & -87 & 16185 \\
\hline Республика Татарстан & 104 & 1353 & 14.5 & 6.4 & 75.9 & 26 & 24010 \\
\hline Республика Тыва & 97 & 1911 & 26.7 & 18.1 & 53.9 & -119 & 11933 \\
\hline Удмуртская Республика & 99 & 1803 & 15.3 & 8.5 & 65 & -27 & 16411 \\
\hline Республика Хакасия & 98 & 2073 & 16 & 12.9 & 67.7 & -10 & 15991 \\
\hline Чеченская Республика & 77 & 298 & 26.2 & 21.9 & 34.8 & -35 & 15257 \\
\hline
\end{tabular}


Таблииа 1 (продолжение)

\begin{tabular}{|c|c|c|c|c|c|c|c|}
\hline Регион & EQ & $\Pi$ & $\mathbf{P}$ & MC & $\mathbf{y}$ & $\mathbf{M}$ & Д \\
\hline Чувашсккая Республика & 101 & 1328 & 14 & 5.3 & 59.8 & -36 & 13755 \\
\hline Алтайский край & 101 & 1752 & 13.7 & 10.1 & 55.5 & -26 & 13629 \\
\hline Краснодарский край & 105 & 1243 & 13 & 6.6 & 53.5 & 87 & 21077 \\
\hline Красноярский край & 98 & 2061 & 14.5 & 9.7 & 76.6 & 13 & 22138 \\
\hline Приморский край & 96 & 2466 & 12.6 & 10.4 & 76.6 & -6 & 21300 \\
\hline Ставропольский край & 97 & 1276 & 12.6 & 11.1 & 57.6 & 8 & 16877 \\
\hline Хабаровский край & 94 & 1977 & 13.8 & 11.5 & 81.5 & -4 & 25649 \\
\hline Амурская область & 89 & 2185 & 14.3 & 13.8 & 67.1 & -53 & 21469 \\
\hline Архангельская область & 103 & 1903 & 12.8 & 7.1 & 76.6 & -85 & 23636 \\
\hline Астраханская область & 94 & 2045 & 15.1 & 9.3 & 66.7 & -36 & 17773 \\
\hline Белгородская область & 100 & 968 & 11.6 & 7.1 & 66.6 & 56 & 21563 \\
\hline Брянская область & 92 & 1488 & 11.4 & 8.9 & 69.3 & -37 & 17422 \\
\hline Владимирская область & 98 & 1525 & 11.5 & 7.8 & 77.6 & -20 & 16136 \\
\hline Волгоградская область & 96 & 1512 & 11.7 & 11.1 & 76.3 & -27 & 16066 \\
\hline Вологодская область & 93 & 1990 & 14 & 8.4 & 71.3 & -9 & 18125 \\
\hline Воронежская область & 100 & 1188 & 10.9 & 6.6 & 66.3 & 43 & 18885 \\
\hline Ивановская область & 97 & 1517 & 11.1 & 6.1 & 81.1 & 10 & 15930 \\
\hline Иркутская область & 93 & 2481 & 15.9 & 9.6 & 79.5 & -30 & 17720 \\
\hline Калужская область & 101 & 1468 & 11.7 & 10.2 & 75.9 & 14 & 20621 \\
\hline Камчатский край & 86 & 1663 & 13.1 & 11.3 & 77.1 & -2 & 31482 \\
\hline Кемеровская область & 99 & 2386 & 13.8 & 8.8 & 85.5 & -17 & 18386 \\
\hline Кировская область & 102 & 1604 & 12.8 & 7.1 & 74.8 & -39 & 16530 \\
\hline Костромская область & 96 & 1265 & 12.9 & 7.8 & 70.5 & -11 & 15808 \\
\hline Курганская область & 91 & 2251 & 13.9 & 8.7 & 60.7 & -97 & 16019 \\
\hline Курская область & 101 & 1347 & 12 & 7.4 & 66.5 & 26 & 18808 \\
\hline $\begin{array}{l}\text { Санкт-Петербург и } \\
\text { Ленинградская об́ласть }\end{array}$ & 111 & 1146 & 11.7 & 4.9 & 91 & 152 & 25246 \\
\hline Липецкая область & 93 & 1158 & 11.7 & 8.4 & 64 & 5 & 19777 \\
\hline Магаданская область & 88 & 2108 & 12.6 & 8.4 & 95.8 & -137 & 36576 \\
\hline $\begin{array}{l}\text { Москва и Московская } \\
\text { область }\end{array}$ & 110 & 1531 & 11.5 & 7.8 & 92.4 & 123 & 41613 \\
\hline Мурманская область & 99 & 1834 & 11.8 & 6.6 & 92.7 & -101 & 28604 \\
\hline Нижегородская область & 104 & 1676 & 11.8 & 8.8 & 79.1 & 21 & 21518 \\
\hline
\end{tabular}


Таблица 1 (окониание)

\begin{tabular}{|c|c|c|c|c|c|c|c|}
\hline Регион & EQ & II & $\mathbf{P}$ & MC & $\mathbf{y}$ & $\mathbf{M}$ & Д \\
\hline Новгородская область & 97 & 2018 & 12.1 & 8.2 & 70.5 & -4 & 19649 \\
\hline Новосибирская область & 106 & 1902 & 13.9 & 8.4 & 77.9 & 80 & 20637 \\
\hline Омская область & 98 & 1538 & 14.9 & 8 & 71.8 & -16 & 19469 \\
\hline Оренбургская область & 100 & 1417 & 14.8 & 9.7 & 59.7 & -44 & 16539 \\
\hline Орловская область & 93 & 1699 & 11.2 & 10.5 & 65.8 & -18 & 16762 \\
\hline Пензенская область & 95 & 1001 & 10.8 & 7.2 & 67.7 & -16 & 15765 \\
\hline Пермский край & 105 & 2441 & 14.8 & 8.5 & 75.1 & 7 & 23270 \\
\hline Псковская область & 103 & 1567 & 11.1 & 10 & 70.3 & 4 & 16412 \\
\hline Ростовская область & 98 & 1232 & 11.7 & 9.1 & 67.7 & 9 & 17987 \\
\hline Рязанская область & 102 & 832 & 10.9 & 9.8 & 71 & 22 & 17664 \\
\hline Самарская область & 101 & 1884 & 12.1 & 7 & 80.3 & 16 & 24683 \\
\hline Саратовская область & 99 & 1146 & 11.4 & 7 & 74.8 & 7 & 14243 \\
\hline Свердловская область & 106 & 1659 & 14.3 & 7.4 & 84.1 & 16 & 27709 \\
\hline Смоленская область & 102 & 1737 & 10.5 & 9.6 & 72.5 & 8 & 18250 \\
\hline Тамбовская область & 95 & 1087 & 9.7 & 4.1 & 59.1 & 2 & 17470 \\
\hline Тверская область & 97 & 1905 & 11.6 & 9.5 & 74.9 & 6 & 17247 \\
\hline Томская область & 108 & 2182 & 13.6 & 8.7 & 71.2 & 45 & 17876 \\
\hline Тульская область & 99 & 901 & 10.1 & 6.6 & 78.8 & -2 & 19291 \\
\hline Тюменская область & 92 & 1892 & 17.2 & 6.4 & 78.9 & 59 & 33281 \\
\hline Ульяновская область & 97 & 1280 & 11.5 & 6.9 & 74 & -33 & 16351 \\
\hline Челябинская область & 98 & 2026 & 14.4 & 8.6 & 82.2 & 13 & 19763 \\
\hline Забайкальский край & 87 & 2851 & 16.2 & 7.4 & 66.8 & -69 & 17336 \\
\hline Ярославская область & 99 & 1359 & 11.9 & 8.1 & 81.9 & 44 & 18513 \\
\hline $\begin{array}{l}\text { Еврейская автономная } \\
\text { область }\end{array}$ & 87 & 2184 & 14.1 & 15.5 & 67.9 & -89 & 18151 \\
\hline $\begin{array}{l}\text { Ханты-Мансийский } \\
\text { автономный округ- Югра }\end{array}$ & 94 & 1743 & 17.7 & 4.5 & 91.8 & 32 & 36088 \\
\hline I Морана & $0.28 * * *$ & $0.49^{* * *}$ & $0.48^{* * *}$ & $0.34^{* * *}$ & $0.35^{* * *}$ & $0.15^{*}$ & $0.23^{* *}$ \\
\hline
\end{tabular}

Примечание. ЕQ - образовательные достижения, П - преступность, $\mathrm{P}$ - рождаемость, МС младенческая смертность, У - урбанизация, М - миграция, Д - доходы населения.

${ }^{*}-p<0.05$; $^{* *}-p<0.01$; $^{* *}-p<0.001$. 
достижения, и остальные показатели характеризуются значимой пространственной автокорреляцией. Пространственная автокорреляция образовательных достижений, однако, ниже, чем по большинству других показателей. В связи с этим можно отметить, что процедура оценивания образовательных достижений региона включала усреднение баллов ЕГЭ для всех специальностей всех вузов региона, не учитывалось то, что вузы в регионах могут быть с более или менее престижными специальностями, что число бюджетных мест относительно населения региона может различаться. Представляется целесообразным сделать одной из задач дальнейшей работы определение влияния учета этих моментов.

Двумя показателями, имеющими еще более низкую пространственную автокорреляцию, чем образовательные достижения, являются миграционное сальдо и доходы населения. Такие результаты не является неожиданностью. В работе А.А. Григорьева с соавт. (Grigoriev et al., 2016) отмечалось несоответствие низкой корреляции (0.13) доходов с образовательными достижениями (рассматриваемыми в этой работе как показатель интеллекта населения региона) в РФ данным исследований в ряде других стран; эта низкая корреляция объяснялась тем, что в РФ доходы в регионе в значительной степени определяются добычей нефти и газа, а соответствующие профессии не предъявляют высоких требований к когнитивным способностям. В таком случае не следует ожидать и высокой пространственной автокорреляции доходов населения в регионах РФ: местонахожде- ние полезных ископаемых едва ли характеризуется пространственной автокорреляцией на уровне таких территориальных единиц, т.е. «фактором пространственной нестабильности» доходов населения граничащих друг с другом регионов может выступать наличие полезных ископаемых в одном из них.

Низкая пространственная автокорреляция миграционного сальдо ставит гораздо более сложный вопpoc. Из всех корреляций образовательных достижений с другими показателями, сообщаемых А.А. Григорьевым с соавт. (Там же), самая высокая (0.54) - с миграционным сальдо. В работе, посвященной изучению соотношения образовательных достижений районов Московской области и уровня грамотности населения соответствуюших территорий в XIX в. (Григорьев и др., 2015), миграция рассматривается как один из возможных факторов стабильности во времени образовательных паттернов (миграция более дееспособного населения в более благополучные районы, миграция в силу ассортативности). Представляется вероятным, что такая миграция не только стабилизирует различие регионов, но и имеет тенденцию его увеличивать. Обнаруженная в работе А.А. Григорьева с соавт. (Grigoriev et al., 2016) корреляция образовательных достижений с миграционным сальдо согласуется $\mathrm{c}$ «гипотезой ассортативности», выдвинутой в другой его работе (Григорьев и др., 2015).

Низкая же пространственная автокорреляция миграционного сальдо в некоторой мере, возможно, обусловлена тем, что даже небольшое различие в соседних регионах 
может вызвать довольно значительную миграцию из региона с худшими условиями, причем часть мигрантов предположительно могут переехать в известный им лучший соседний регион. Это приведет к противоположным изменениям миграционного сальдо в соседних регионах, в результате которых различие его значений в этих регионах может стать довольно большим. Некоторое число таких случаев вызывает снижение его пространственной автокорреляции.

В пространственную нестабильность миграционного сальдо может вносить вклад и реакция населения на воспринимаемые различия регионов, и то, что сам показатель фиксирует «обмен» - люди переезжают из одного региона в другой. Мы, вероятно, вообще не должны ожидать высокой пространственной автокорреляции этого показателя, что, однако, не снижает его ценности для макропсихологических исследований. Вообще же вопрос о пространственной автокорреляции показателей, выражающих обмен между регионами, требует специального рассмотрения.

\section{Литература}

Григорьев, А. А., Лаптева, Е. М., Ушаков, Д. В. (2015). Образовательные достижения районов Московской области воспроизводят уровень грамотности в XIX в.: механизмы «культурной генетики». Сибирский психологический журнал, 56, 69-85.

Григорьев, А. А., Сухановский, В. Ю. (2015). География научного творчества. В кн. А. Л. Журавлев, Д. В. Ушаков, М. А. Холодная (ред.), Современные исследования интеллекта и творчества (с. 172-188). М.: Изд-во «Институт психологии РАН».

Министерство образования и науки РФ. (2014). Качество бюджетного приема в государственные вузы РФ по направлениям подготовки - 2014. Режим доступа: http://vid1.rian.ru/ig/ratings/kachestvopriema_napravleniya_budget_2014.pdf

Регионы России. Социально-экономические показатели. 2013. (2013). Режим доступа: http://www.gks.ru/wps/wcm/connect/rosstat_main/rosstat/ru/statistics/publications/cata$\log /$ doc_1138623506156

Ссылки на зарубежные источники см. в разделе References после англоязыиного блока.

Григорьев Андрей Александрович - главный научный сотрудник, ФГБУН Институт психологии РАН, доктор филологических наук, доцент.

Сфера научных интересов: интеллект, индивидуальные различия, психолингвистика. Контакты: andrey4002775@yandex.ru 


\title{
Spatial Autocorrelation of Educational Attainment in the Russian Federation
}

\author{
A.A. Grigoriev \\ ${ }^{a}$ Institute of Psychology of Russian Academy of Sciences, 13 build. 1, Yaroslavskaya str., Moscow, 129366, \\ Russian Federation
}

\begin{abstract}
Spatial autocorrelation is a measure of the degree in which objects, situated in a close proximity, have a tendency for similar values of a given index. Since recently psychology started to study spatial autocorrelation of national IQ (mean intelligence in a country). The article presents the results of the calculation of spatial autocorrelation of educational attainment (calculated from a mean score of the Unified National Exam of young people, who made it into a college for a budget education in 2014), as well as crime, birthrate, infant mortality, urbanization, net migration and personal income for 75 regions (subjects) of the Russian Federation. These results showed that, though all the mentioned indices are characterized by the spatial autocorrelation, its value varies. Low spatial autocorrelation has net migration, which is probably due to the fact that even a slight difference in life conditions between neighbor regions may promote intensive migration from the region with the worse conditions to the regions with better conditions, including the neighboring one. Low spatial autocorrelation of personal income can be explained by the fact that in the Russian Federation personal income in the region to a great extent is determined by oil and gas production, while mineral deposits are hardly characterized by the spatial autocorrelation on the level of such territorial units as subjects of the Russian Federation. Spatial autocorrelation of educational attainment is probably lessened by the fact that the scores were received by averaging the scores of the Unified National Exam for all specialties of all universities of the region without the consideration of possible differences of regions in prestige value of specialties and number of budget places in universities.
\end{abstract}

Keywords: spatial autocorrelation, educational attainments, net migration.

\section{References}

Gelade, G. A. (2008). The geography of IQ. Intelligence, 36, 495-501. doi:10.1016/ j.intell.2008.01.004

Grigoriev, A. A., \& Sukhanovskii, V. Yu. (2015). Geografiya nauchnogo tvorchestva [The geography of scientific creativity]. In A. L. Zhuravlev, D. V. Ushakov, \& M. A. Kholodnaya (Eds.), Sorremennye issledovaniya intellekta i tvorchestva [Modern studies of intelligence and creativity] (pp. 172-188). Moscow: Institute of Psychology of RAS.

Grigoriev, A. A., Lapteva, E. M., \& Ushakov, D. V. (2015). Educational performance of Moscow region districts reproduce their literacy level in the XIX century: mechanisms of the "cultural genetics". Siberian Journal of Psychology, 56, 69-85. (in Russian) 
Grigoriev, A., Ushakov, D., Valueva, E., Zirenko, M., \& Lynn, R. (2016). Differences in educational attainment, socio-economic variables and geographical location across 79 provinces of the Russian Federation. Intelligence, 58, 14-17. doi:10.1016/j.intell.2016.05.008

Hassall, C., \& Sherratt, T. (2011). Statistical inference and spatial patterns in correlates of IQ. Intelligence, 39(5), 303-310. doi:10.1016/j.intell.2011.05.001

Regiony Rossii. Social'no-jekonomicheskie pokazateli. 2013 [Regions of Russia. Social economic indices]. (2013). Retrieved from http://www.gks.ru/wps/wcm/connect/rosstat_main/rosstat/ru/statistics/publications/catalog/doc_1138623506156

The Ministry of Education and Science of the Russian Federation. (2014). Kachestro byudzhetnogo priema v gosudarstvennye zuzy RF po napravleniyam podgotovki - 2014 [The quality of budget admissions to the state universities of the Russian Federation according to the training program - 2014]. Retrieved from http://vid1.rian.ru/ig/ratings/kachestvopriema_napravleniya_budget_2014.pdf

Andrei A. Grigoriev - chief research fellow, Institute of Psychology of Russian Academy of Sciences, D.Sc., associate professor.

Research area: intelligence, individual differences, psycholinguistics.

E-mail: andrey4002775@yandex.ru 